\title{
Grades degrade group coordination: deteriorated interactions and performance in a cooperative motor task
}

\author{
Anne-Sophie Hayek ${ }^{1}$ - Claudia Toma ${ }^{2}$ • Sofia Guidotti ${ }^{1}$ • \\ Dominique Oberlé $^{3} \cdot$ Fabrizio Butera ${ }^{1}$
}

Received: 9 March 2015 /Revised: 6 January 2016 / Accepted: 11 January 2016 /

Published online: 23 January 2016

(C) Instituto Superior de Psicologia Aplicada, Lisboa, Portugal and Springer Science+Business Media Dordrecht 2016

\begin{abstract}
At school, pupils often cooperate on common projects and must coordinate their different individual actions. However, grades are pervasively used even in cooperative situations, which make the pupils' differences in achievement and their relative rank salient and may reduce their inclination to work constructively with others. Thus, we hypothesized that grades would elicit disruptive interactions and reduce performance in a cooperative cognitive-motor task necessitating inter-individual coordination of members. In a study with 5 th graders, grades (vs. a neutral concept) were primed at the onset of a cooperative group interaction. Results showed that, although pupils were set to work cooperatively, priming grades (vs. neutral concepts) harmed inter-individual coordination by eliciting more negative dominant behaviours among pupils during interactions, which decreased group performance.
\end{abstract}

Keywords Grades · Inter-individual coordination · Cooperation · Dominant behaviours

Teachers often require from pupils to cooperate on a common project, which may require a certain degree of coordination of the different individual actions. This practice is often built on the idea that cooperating on a group work will benefit pupils' learning, the quality of their interactions and the final product of the group (Buchs et al. 2004; Johnson et al. 2007; Roseth et al. 2008). At the same time, grades are pervasively used in schools to assess the work of individual pupils, with the effect

Fabrizio Butera

Fabrizio.Butera@unil.ch

1 Institut des Sciences Sociales, Université de Lausanne, Lausanne, Switzerland

2 Université Libre de Bruxelles, Brussel, Belgium

3 Université de Paris Ouest Nanterre La Défense, Nanterre, France 
of making the pupils' differences in achievement and their relative rank salient (Pulfrey et al. 2011), which may reduce people's inclination to work constructively with others (Darnon et al. 2006) and to appreciate other people's information (Hayek et al. 2014).

Thus, in a cooperative group work setting that implies the coordination of its members' actions (McGrath et al. 1999), it is possible that grades alter group cooperation, when defined as members' capacity to coordinate their actions and efforts towards the joint achievement of a task. Indeed, although a fair amount of research has shown that grades may yield negative effects on individual motivation (e.g. Pulfrey et al. 2013), performance and learning (e.g. Kohn 1993), there is a dearth of research studying the effects of grades on group work. One exception would be Hayek et al. (2015) experiments, which showed that expectation of being individually graded in a cooperative group reduced the sharing of useful information and increased the sharing of useless information. However, no research - to the best of our knowledge - tested the impact of grades on inter-individual coordination, a direct indicator of cooperation. Hence, in the present work, we test the hypothesis that grades undermine group cooperation under the form of inter-individual coordination, in a study with 5 th graders.

\section{Grades in educational settings: comparative, ego-involving and threatening}

Starting from elementary school, pupils are socialized to be assessed with grades and to understand the importance of grades for their future success (Anderman and Midgley 1997). Indeed, during this process, pupils increase their focus on concerns about their self-ability or their performance relative to others when achieving a task, as opposed to a focus on learning and mastering the task (Pintrich 2000a; Anderman and Young 1993). In other words, pupils discover the importance of achieving relative to other students (e.g. the ranking emphasis), that is the importance of norm-referenced assessments (Brookhart 2004).

In this respect, grades hold two entwined characteristics, namely being ego-involving and enhancing social comparison. Indeed, grades are ego-involving (as opposed to task-involving; Nicholls 1979, 1983) to the extent that they imply important consequences in terms of status and selection in the class. They focus individual's "attention on the self by emphasizing outcome or social comparison (or both), rather than process or task mastery" (Butler 1987, p. 475). These two characteristics are important for the present research, to the extent that comparison to a normative standard may prompt a threatening comparison (Muller and Butera 2007) that has been shown to be deleterious for peer relations and learning (Butera et al. 2006; Mugny et al. 2003). Hence, if grades highlight the importance of performing well as compared to others, they could be pressuring for group performance because "any factor or combination of factors that increases the importance of performing well on a particular occasion" (Baumeister 1984, p. 610) creates pressure and may result in performance impairment (Crouzevialle and Butera 2013). More to the point, Darnon and Butera (2007) asked their participants to interact on a controversial issue, and experimentally manipulated the importance of performing well as compared to others by inducing performance goals (demonstrate competence as compared with others) vs mastery goals (acquire knowledge) or control (no goal instruction). Results showed that in the performance goal condition-but not in the two other conditions - controversy predicted a tendency to affirm one's own competence over that of others. Thus, it is possible that grades reduce inter-individual coordination in groups. 


\section{Inter-individual coordination, an indicator of group cooperation}

Inter-individual coordination can be viewed as the means by which actions of individuals are joined towards the successful achievement of a common goal. In other words, coordination is an indicator of cooperation in that it supports and enhances cooperation when it is finely achieved (Johnson and Johnson 2009a). Hence, in a cooperative task where coordination is necessary for good group performance (e.g. The cooperative game, Doise and Mugny 1981), a finely achieved coordination should impact performance on the task (task-focus level; Bales 1950). Similarly, fine coordination reflecting group cooperation should impact the relational level of group functioning (i.e. group-focus level). It is what Barron (2000) observed when analysing interactions of 6th-grade boys triads set to work collaboratively on a problemsolving task (i.e. a trip-planning problem, cf. Barron 2000, p. 410). The triad in which members coordinated their responses gave complete and accurate solutions, its members initiated complementary roles, had comfortable inter-individual relations and treated common material as a "centre of coordination" (ibid. p. 430). The triad where coordination failed gave partial solutions, its members struggled with lack of control, bad communication, and treated the common material as a "contested territory" (p. 430). Hence, to study coordination as an indicator of successful cooperation, it is crucial to use a task where inter-individual coordination of actions and constructive inter-individual relations are functional to task success.

\section{The Cooperative Game}

These characteristics feature in the "Cooperative Game" (Doise and Mugny 1984), a cognitivemotor task initially created to study cooperation as a dynamic process of cognitive development in children. In its version for three players, the device requires from players to use pulleys to coordinate their hand-eye movements in order to successfully achieve a go on a board game (cf. Methods and Appendix). Hence, the better they coordinate their movements, the higher the group performance. Furthermore, to coordinate, players are allowed to speak, gesticulate, but not to leave their position. Therefore, speech and gesture are prevailing modes of communication (Schmid Mast 2002; Tusing and Dillard 2000) as they facilitate monitoring one another's work (Forman and Cazden 1985), and the better they communicate, the higher the group performance.

Thus, in the present task, performance is dependent upon coordination at two levels. At taskfocus level, performance is the direct expression of motor coordination, to the extent that the movement of the ball pen requires that the three partners roll and unroll their pulleys at the same time. All actions that attempt to show one's superiority over the others, as for instance pulling all the time, may therefore impair performance. At group-focus level, performance depends on positive relations and communication of relevant information and action intentions. All communications that reveal a struggle for control, such as for instance giving orders to others, in terms of negative dominant behaviours may therefore impair performance. Indeed, when individuals exhibit social dominant behaviours, they "successfully manage to control resources in the presence of others, regardless of how they do it" (Hawley 2002, p. 168). However in order to control resources, individuals can use two types of strategies that reflect dominant behaviour: Make use of rather pro-social strategies (i.e. use of pro-social behaviours as an effective resource control strategy), or use rather coercive strategies (i.e. monopolizing to control resources). Among the two types of social dominant behaviours, only the pro-social behaviour is associated with social competence and is positively evaluated by peers. On the contrary, negative or coercive 
social dominance can be maladaptive and can disrupt cooperation (Rubin and Rose-Krasnor 1992). Indeed, several studies suggest that negative social dominance may interfere with group performance, under the form of behaviours such as interruptions in discussions (Brody and SmithLovin 1989), interruptions during interaction (Zapiti and Psaltis 2012), authoritarian gestures (Dunbar and Burgoon 2005) and intrusive behaviours (touching and pointing at others; Leffler et al. 1982). More generally, Psaltis and Zapiti (2014) noted that dominant behaviours aiming at controlling the partner(s) are disruptive for performance as well as learning.

Thus, we decided to focus only on the negative social dominant behaviours because, as previously mentioned, this is the type of behaviours that are expected to disrupt cooperation. More precisely, if grades are ego-involving and represent a potentially competitive social comparison, they should lead individuals to try to put themselves forward during the Cooperative Game interactions, and therefore to try to monopolize the action. In sum, negative social dominant behaviours can be operationalized by "floor-taking" control indices (i.e. monopolization), as well as indices of emotional negative tension, thereby capturing at once the social dominance part of the behaviour and its negative valence.

\section{Hypotheses}

We have shown in the first section of this introduction that grades create an evaluative pressure that focuses individuals on performance relative to others (Butler 1987), which is known to promote assertion of one's own competence over that of the other (Darnon and Butera 2007). We have also shown in the last section how performance at a cooperative task relying upon inter-individual coordination would be impaired by such a dominant behaviour, both at the motor coordination and at the communication level. Thus, we hypothesize that the presence of grades should deteriorate interactions among individuals, under the form of negative dominant behaviours (Hypothesis 1), as well as group performance in the cooperative game (Hypothesis 2 ), in comparison to groups working in a grades-free environment.

Although we did not have a specific hypothesis regarding the effect of age and gender, previous research has shown that grades and other forms of individual reward differentially impact individual and group work as a function of age (e.g. Leman 2015) and gender (e.g. Walton and Cohen 2003). Thus, we controlled the effect of these variables.

\section{Method}

\section{Participants and design}

Participants were 132 5th-grade pupils enrolled in two elementary schools in the Italianspeaking canton in Switzerland; before the experiment, we obtained the agreement of the school's headmaster and the teachers, as well as the signed authorization of the children's parents. Participants were randomly assigned to 44 three-person groups; 2 groups were excluded from the analyses, one because a member had a motor disability, and another because a member had concentration problems. The 42 remaining groups were randomly assigned to the two experimental conditions: 20 in the Neutral Priming condition and 22 in the Grades Priming condition $(M=10.22$ years, $\mathrm{SD}=.23)$. Among the 42 groups, 26 were composed of a majority of girls and 16 by a majority of boys. 


\section{Materials and procedure}

Materials The "cooperative game" device was composed of a board game (comprising a three-lane trail: inner, middle, outer lanes, delimited into squares, with a start/finish square; cf. Appendix, panel B), three pulleys fixed on the board game and connected together by strings linked to a device supporting a ballpoint pen (cf. Appendix. panel A). Pulleys could be adjusted in two ways making it more or less hard for players to roll/unroll them: pulleys loosened vs. strengthened ${ }^{1}$. Therefore, groups performed two goes: one with loosened pulleys, another with them strengthened (the order was counter-balanced). The two adjustment modes have been used because they were part of Doise and Mugny's (1984) materials.

Procedure Pupils were randomly sent by their teacher to the classroom where the experiment was taking place in groups of three. Once inside, they were placed around the Cooperative Game, each standing behind a pulley. The experimenter explained that their goal was to move forward the pen, from the first to the last square, without drawing out the middle lane; to this effect, they would have to only use the pulleys and to coordinate them. The experimenter added that the label taped on the side of the board game concerned a previous experiment and that it was not to be removed; accordingly, she attracted attention on the label, amounting to supraliminal priming. In supraliminal priming or conscious priming, the participant is exposed to the priming stimuli as part of a conscious task. That is, the individual is fully aware of the priming stimuli itself, but is not aware of some underlying pattern that serves to prime the construct (Bargh and Chartrand 2000). In the Grades Priming condition, the label depicted a scale of grades ranging from 2 (very bad) to 6 (excellent), which is the range of grades used in the Swiss educational system (cf. Appendix, panel C). In the Neutral Priming condition, the label had the same graphical appearance as in the other condition, but it represented a scale converting $1 \mathrm{~m}$ into different units (ranging from millimetres to kilometres). This manipulation was adapted from Hayek et al. (2015, experiment 2), who successfully used it with adult participants. As discussed by these authors, this method has the advantage of activating grades without incurring the risk that the actual distribution of grades creates a negative goals interdependence among group members in a task that is supposed to be based on cooperation, that is positive goals interdependence.

Then, the experimenter demonstrated on one pulley how the device worked, pointing out that when pulleys were tightened they were difficult to roll and one had to intentionally roll and unroll one's own pulley, making it useless to pull in order to unroll someone else's pulley. On the reverse, when loosened, rolling one's pulley could exert an indirect control on the pulley of another participants. After these instructions, the experimenter withdrew to a corner of the room, leaving participants to perform the first go. Then, the experimenter inverted the pulleys' setting (strengthening or loosening them) and leaving participants to achieve their second go. The experiment ended when groups finished the second go. The overall experiment lasted about 20 min per group (the exact time to perform each go was recorded, see below) and interactions were videotaped. The participants were thanked and debriefed; at the end of the

\footnotetext{
${ }^{1}$ The first setting (pulleys strengthened), initially designed to restrict players' non-intentional movements (cf. Doise and Mugny 1997), required from players to intentionally release their pulley to allow other players to pull, making it impossible for other players to pull strong enough on their own pulley and control the others' pulley's release. In the second setting (pulleys loosened), the pulleys are not locked, allowing players to unroll the others' pulley simply by pulling
} 
experiment, the teachers received a full written account of the experiment, to be shared with the pupils and the parents.

\section{Dependent measures}

Overview of dependent measures All dependent measures presented below were repeated measures, measured and computed for each go.

Amount of negative dominant behaviours (NDBs) Regarding the observation of social dominant behaviours, we decided to focus only on the emission of negative dominant behaviours because, contrary to positive dominant behaviours, they are the ones expected to disrupt cooperation. We decided to operationalize the NDB variable by computing an indicator that captures at the same time the social dominant part of the behaviour and its negative affects (see below). We computed the amount of NBDs produced at group level, based on the observation of both verbal and non-verbal micro-level behaviours. Indeed, negative dominant behaviours can be measured by "floor-taking" indices, such as the number of oral interventions to give orders to others, and the voice intonation used (Bales 1950).

Three micro-level behaviours were coded by two coders, who were blind to the experimental condition. In order to reach a consensual coding - and as averaging the two coders' ratings would not make sense for these DVs - we decided to have the two coders discuss the few disagreements that emerged and come up with a single judgment on whether or not a specific behaviour constituted an NDB. In this respect, in the end, coders agreed in all instances.

The final total score consists of the sum of (a) the number of verbal orders addressed to others to tell them what to do (e.g. "Pull forward now!"), (b) the number of verbal orders simultaneously expressed with intrusive behaviours to tell others what to do (e.g. One participant telling another "Pull the pulley!" while simultaneously dropping his/her own pulley in order to mime the action), and (c) verbal interventions with tones of emotional negative tension (i.e. annoyed and scornful tones, e.g. "arrggggghhhh, no, not that way!", "are you stupid or what?").

Performance Group performance scores for each go were calculated by respectively adding +1 point for each square when the drawn line was inside the middle lane; 0 point, when it went over-line and entered the inner or outer lane; and -1 point, when it went out of the whole threelane trail figure.

The task was new to the participants and likely to display an increase in performance throughout the experiment, whereby with time the group members become more acquainted with the task and with their fellow group members, and more effective at coordinating their work. To investigate the evolution of group performance during each go, the path was divided in three parts (Beginning, Middle, End). Given that the three parts did not hold an equal number of squares, sub-scores of performance based on raw data were not comparable ${ }^{2}$;

\footnotetext{
${ }_{2}$ The Start/Finish square was not included in the coding of group performance because we realized afterwards that the instructions were ambiguous as to whether the Start square was to be considered as the Finish, and some groups stopped before reaching this last square. Thus, the Beginning (from square no. 1 to square no. 48) and Middle of the game (from square no. 49 to square no. 96) both contained an equal subtotal of 48 squares, whereas the End of the game (from square no. 97 to square no. 143) contained a subtotal of 47 squares.
} 
therefore, we calculated a percentage of performance for each part, dividing the actual performance sub-score obtained on each part by the maximum performance score that could have been theoretically expected on each part (that is, 48 points for Beginning and Middle parts, 47 points for the End part), and multiplying by 100 .

\section{Results}

\section{Overview of analyses}

Age of participants and the school they attended were introduced in preliminary analyses, but, as no effect was found, they were removed from the final analysis. Preliminary analyses on group performance and negative dominant behaviours revealed a significant main effect of Time to perform the 1st go. Therefore, Time to perform each go was kept in the model. No main effect of Order of goes or Group gender composition was found; thus, to the extent that they were only control variables, we removed Order of goes (i.e. the following results concern both goes) and Group gender composition from the analyses.

\section{Amount of negative dominant behaviours}

The amount of negative dominant behaviours was analysed with a 2 (Experimental manipulations: Grades Priming, Neutral Priming) $\times 2$ (Goes: 1st go, 2nd go). However, one group was detected as an outlier (with a Studentized Deleted Residual of 3.07 and a Cook value of .23 , i.e. superior to $4 / N=4 / 42=.09$ ) and was removed from the analysis. The remaining sample included 41 groups, 22 in the Grades Priming condition and 19 in the Neutral Priming condition. The analyses revealed a main effect of time to perform on the first Go, $F(1,37)=33.23$, $p<.001, \eta p^{2}=.47$, and an interaction effect of the within-participants variable Goes with Time showing that the effect was stronger on the first Go, $F(1,37)=115$. 44, $p<.001, \eta p^{2}=.76$, than on the second Go, $F(1,37)=86.53, p<.001, \eta p^{2}=.70$. More importantly, the model revealed a main effect of the priming manipulation, indicating that groups in the Grades Priming condition used more negative dominant behaviours when interacting with others $(M=89.27 ; \mathrm{SD}=44.14)$ than groups in the Neutral Priming condition $(M=58.92 ; \mathrm{SD}=24.17), F(1,37)=3.91, p=.056, \eta p^{2}=.10$, thereby supporting Hypothesis 1.

\section{Performance}

Performance was initially analysed with a 2 (Experimental manipulations: Grades Priming, Neutral Priming) $\times 3$ (Parts of the Game: Beginning, Middle, End) X 2 (Goes: 1st go, 2nd go) General Linear Model (GLM) with repeated measures on the last two factors and Time to perform each go as covariate. However, because there was no main effect or interactions with the Goes (1st go, 2nd go), we dropped this factor from the model and used the mean score of the 1st and 2 nd go. Thus, Performance was analysed with a 2 (Experimental manipulations: Grades Priming, 
Neutral Priming) $\times 3$ (Parts of the Game: Beginning, Middle, End) GLM with repeated measures on the last factor and Time to perform each go as covariate.

In the mixed-model GLM that we ran, we included the linear contrast $\mathrm{c} 1(-1,0$, $+1)$ to investigate the evolution of performance on the Parts of the Game, where $(-1)$ related to the Beginning, (0) the Middle and (+1) the End parts of the Game, a contrast that should be significant if - as it could be expected-practicing the Game produces an increase in performance. The mixed-model GLM revealed, however, no significant main effect of the linear contrast $\mathrm{c} 1$ testing the evolution of performance across the Parts of the game, $F<1$. The quadratic, orthogonal contrast c2 $(-1,+2,-1)$ was not significant either, $F(1,38)=2.12, p=.15$. The effect of the experimental manipulation was not significant, $F<1$, nor was the interactions between the manipulation and the linear contrast $F<1$, or between the manipulation and the quadratic contrast, $F<1$. The only significant effect was that of the covariate Time to perform the 1 st go, $F(1,38)=7.12, p<.01, \eta p^{2}=.16$, which confirms what was found in the preliminary analyses.

Notwithstanding the overall lack of effects, it is interesting to note that we did not observe a significant increase in performance from one phase to another, which would have been reasonable to expect because of the increased familiarity with the task as the game progresses (cf., the importance of observation, Bandura 1986; Pollock and Lee 1992, and physical practice in motor learning, Blandin 2002). If anything, inspection of the means show a non-significant performance decrement between the Beginning and the End parts of the game (see Fig. 1). A possible interpretation of this non-significant, albeit suggestive trend, present in both goes, could be that pressure to achieve increases towards the end of the game and disrupts coordination and therefore

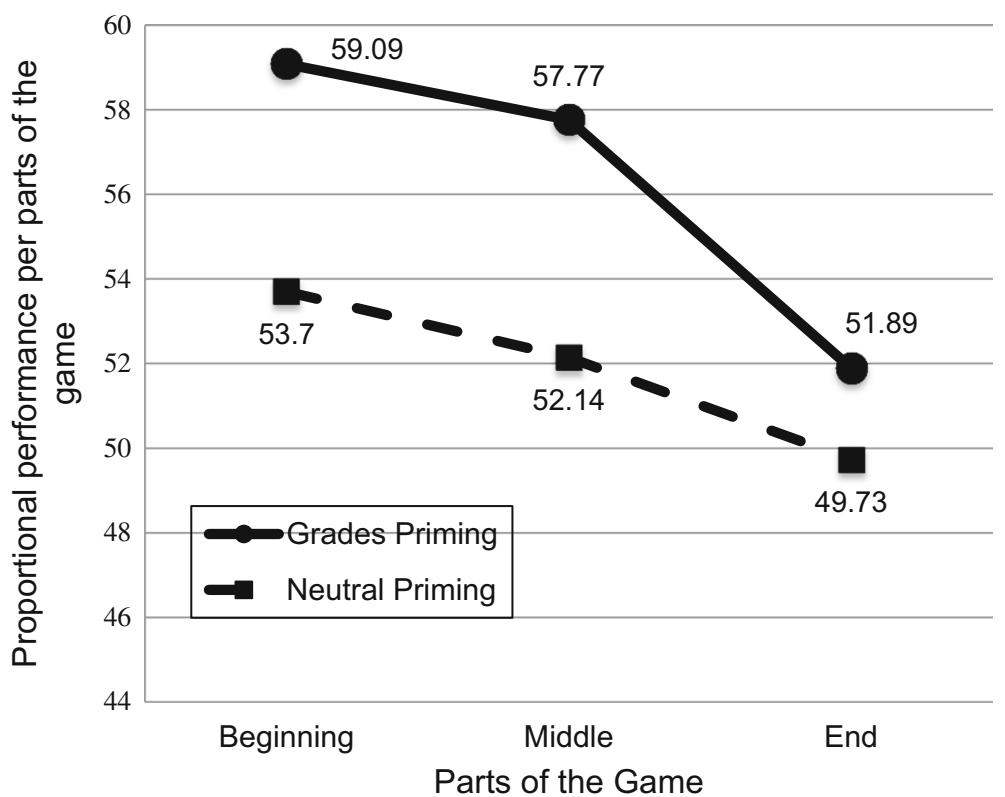

Fig. 1 Evolution of groups' proportional performance across the three main parts of the game, as a function of experimental manipulations 
performance. In order to study this possibility in more details, we divided the End part of the game in two sub-parts: the Before-Home Straight and the Home Straight. Then, we run the same analyses with a within-participants variable comprising four parts: Beginning, Middle, Before-Home Straight and Home Straight. As the four parts do not include the same number of squares, the analyses were again run on the proportional performance during each phase; the percentages for the Beginning and Middle parts remained the same, and we computed the score for the two new parts by again dividing the raw score of performance obtained on each part by the maximum performance score, namely 30 points for the Before-Home-Straight (square no. 97 to square no. 126) and 17 points for the Home-Straight (square no. 127 to square no. 146), and multiplying it by 100 .

In the same GLM model previously run, we entered the within-participant Helmert contrasts $\mathrm{c} 1(+3,-1,-1,-1)$, c2 $(0,+2,-1,-1)$ and $\mathrm{c} 3(0,0,-1,+1)$ to investigate the evolution of performance across the Parts of the Game, namely the Beginning, the Middle, the Before-Home Straight and the Home Straight. Again, a significant main effect of the covariate Time to perform on the 1 st Go was found, $F(1,38)=5.89$, $p<.01, \eta p^{2}=.13$. More importantly, the analysis showed a significant multivariate interaction effect between the Parts of the Game and the Experimental Manipulations, $F(3,36)=4.34, p<.01, \eta p^{2}=.27$. Inspection of the means suggest that this effect may be due to the differences in performance occurring within the End part of the game (see Fig. 2), which was confirmed by the significant interaction effect between the within-participant contrast $c 3$, opposing the two last parts of the Game, and the Experimental manipulation, $F(1,38)=12.33, p<.001, \eta p^{2}=.25$. It appeared indeed that groups in the Grades Priming condition decreased their performance from BeforeHome-Straight $(M=57.05 ; \mathrm{SD}=.18)$ to the Home-Straight $(M=42.78 ; \mathrm{SD}=.19)$,

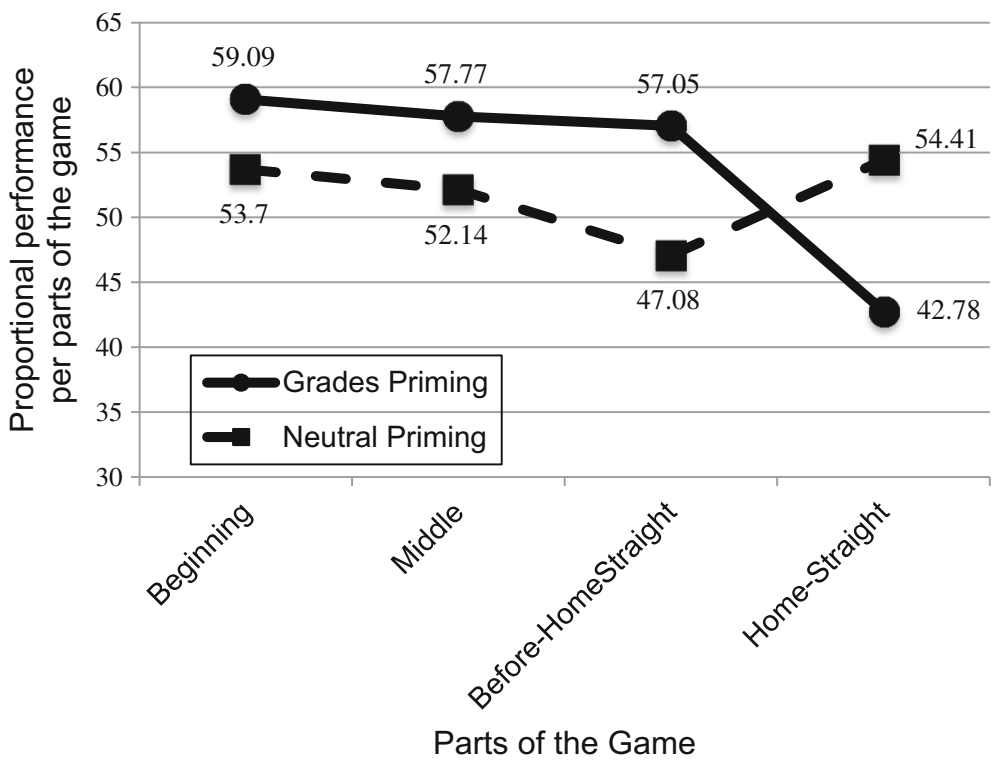

Fig. 2 Evolution of groups' proportional performance across the four parts of the game, as a function of experimental manipulations 
whereas groups in the Neutral Priming condition increased their performance from Before-Home-Straight $(M=47.08 ; \mathrm{SD}=.16)$ to the Home-Straight $(M=54.41$; $\mathrm{SD}=.22$ ). Finally, it is important to note that, during the Home-Straight phase, groups in the Grades Priming condition performed significantly worse than groups in the Neutral Priming condition, $F(1,38)=5.59, p<.05, \eta p^{2}=.13$.

\section{Mediation analyses}

Given the effect of our priming manipulation on the amount of negative dominant behaviour, we tested whether the dominant behaviour mediated the effect of priming on the overall performance. We followed the more recent recommendations to test for the indirect effect of negative dominant behavior in the absence of the total effect of priming on performance, which could be due here to the low sample size (Rucker et al. 2011). To test for the indirect effect, we computed an overall score of performance as the mean of performance calculated on different parts of the game (Beginning, Middle, End). We used the bootstrapping method (Hayes 2013) in which priming manipulation was the independent variable $(\mathrm{X})$, negative dominant behaviour was the mediator $(\mathrm{M})$ and overall performance was the dependent variable $(\mathrm{Y})$.

The mediation model was estimated with 1000 iterations using the PROCESS macro for SPSS. The estimated indirect effect of dominant behaviour on performance was .0425 ( $\mathrm{SE}=.0224)$ with a $95 \%$ confidence interval of .0042 to .0904. The confidence interval did not include zero, indicating that negative dominant behaviour significantly mediated the effect of priming on performance. This suggests that priming participants with grades led them to adopt more negative dominant behaviors, which in turn were responsible for the decrease in performance.

\section{Discussion}

The present study investigated, on a sample of 5th grade pupils, the effects of merely activating grades prior to a cooperative task on group members' subsequent interpersonal coordination. The effect of grading individuals on individual performance has been widely studied (e.g. Butler 1987), and so has the effect of grading groups on individual performance (for a discussion, see Buchs et al. 2011), but Social and Educational Psychology have remained silent on the effects of grading on group performance. This is an important gap in the literature, to the extent that it leaves unstudied a rather frequent situation, namely that of group work at school, where grading is pervasive.

To address this question, we selected a task, the cooperative game (Doise and Mugny 1984), which requires from individual group members to coordinate the actions of their pulleys and move a ball pen along a trail, thereby making cooperation necessary to good performance. Because grades are known to produce an evaluative pressure likely to be threatening and requiring to enhance one's competence over that of the others (e.g. Butera et al. 2006), we hypothesised that the presence of grades, as compared to the absence of grades, would hamper interactions among individuals, 
under the form of negative dominant behaviours (Hypothesis 1), as well as group performance (Hypothesis 2).

The results showed that priming the pupils with grades (in comparison to a neutral priming) resulted in tenser relations during the game, and more floor-taking control and intrusive behaviours to direct others, which supported our first hypothesis.

The results also showed that priming the pupils with grades from the onset of the game (in comparison to a neutral priming) indeed resulted in lower group performance, in partial support of our second hypothesis. The support is partial because the analyses revealed that this difference is not significant for the total performance across the three parts of the game, but - after dividing the game in four, rather than three parts - only for the very last part, which we have called the Home-Straight. This is, admittedly, an unexpected result. However, we decided to report both the nonsignificant results obtained with the a priori division in three parts and the significant results obtained with the post-hoc division in four parts, not only for reasons of clarity and transparency but also because we believe that this unexpected result supports - rather than undermines - the theoretical rationale of our Hypothesis 2.

Let us see how this might be. The evolution of the measure of performance across the parts of the game showed that-instead of increasing, as it would be reasonable to expect when participants become more and more acquainted with the task-it stagnated from the beginning to the end of the task (it even slightly, but non-significantly decreased). We reasoned that this could be an indicator of some threat, or other form of difficulty, occurring toward the end of the game; thus, we decided to further divide the trail in four parts, so as to single out the final part that goes straight to the arrival: the Home-Straight. The results showed that the performance of the groups in the Grades Priming condition decreased their performance as they moved into the HomeStraight, a decrease that was not observed in the Neutral Priming condition; moreover, it is indeed during the Home-Straight that the groups' performance is significantly lower in the Grades Priming than in the Neutral Priming condition. We interpret this result as a support to our hypothesis, as we hypothesized that grading may impair group coordination because it has the potential to create a threatening evaluative pressure (e.g. Pulfrey et al. 2011), and the expected impairment occurred precisely in the part of the game where the pressure is likely to be the highest.

Finally, the mediation analysis revealed an indirect effect. The condition in which grades were primed, compared with neutral priming, led participants to a higher amount of negative dominant behaviors, which in turn were responsible for the decrease in performance.

These results allow discussing two important theoretical consequences. Firstly, this study shows that although work instructions called for group cooperation-and actually the very task structure required coordinating actions - the mere mention of grades in a peripheral area of the board managed to weaken that cooperative structure. The written mention of grades reduced both inter-individual coordination and the potential for group relations to be constructive. One limitation of this study is the absence of possible mediators of these effects. Thus, future studies should most definitely anticipate this methodological gap and should focus on the role of threat and achievement goals, as possible mediators. However, this study suggests that the self-evaluation 
threat implied by grades is so rooted in pupils that the mere mention of grades may activate the threat and impair group performance and intra-group relations.

Also, although the Cooperative Game has been used in numerous studies (cf. Doise and Mugny 1981), it should be acknowledged that the present results have been tested only with one task. To generalize the present findings, an interesting follow-up study would use a task that would be more representative of those used in classrooms while still requiring coordination. A possibility would be to use Barron's (2000) collaborative-problem solving task or even a more ecological task, e.g. a research intervention that would take place during sports classrooms in which children experience group coordination activities with their teachers. However, it is possible that the present results are limited to tasks that require coordination, as in some tasks joint performance can be perfect even if one of the partners is doing all the moves and the other is completely passive and dominated (e.g. spatial perspective taking, Mugny and Doise 1978).

Secondly, we note that the deleterious effect of grades was obtained on a sample of young participants: pupils in the 5th grade of elementary school. It would be interesting to investigate the effect of grades on samples drawn from higher academic levels where the emphasis on performance goals is even stronger (Midgley et al. 1995; Harackiewicz et al. 1998), in order to see whether grades could elicit more accentuated effects. But it would also be interesting to replicate this experiment with younger samples, to discover how many years of acquaintance with the grading system are sufficient to produce the same effect observed in the present study.

Finally, these results allow discussing the understanding of dominant behaviours in terms of resource control strategies (coercive-dominant or pro-social) as studied by developmental psychologists like Hawley (1999, 2002). According to this author, the use of one type of control strategy or another depends on personal orientation and stage of cognitive development: At different ages, children's personal social orientation and their goal structure can orient towards one strategy over the other (coercivedominant or pro-social strategies) to control others' resources (e.g. "coercive children may be less motivated by personal relationships or motivated largely by instrumental goals such as access to material goods or power"; Hawley 1999, p. 116). The present results showed how an environmental factor (i.e. grades) could elicit negativedominant behaviours. This underlines the importance of taking into account structural factors that may be taken for granted, such as the use of grading, when studying group behaviour and performance.

Acknowledgments This work was supported by the Swiss National Science Foundation, and is part of AnneSophie Hayek's doctoral dissertation under the supervision of Fabrizio Butera and Dominique Oberlé.

\section{Appendix}

Picture of the Cooperative Game (adapted from Doise and Mugny 1984), kindly lent by Gabriel Mugny. Panel A: the device. Panel B: the trail. Panel C: the grades prime (with the original terms in Italian). 
A

B

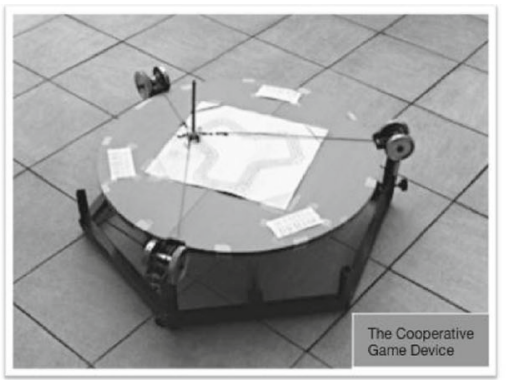

\section{B}

The Cooperative Game (Doise \& Mugny, 1981)

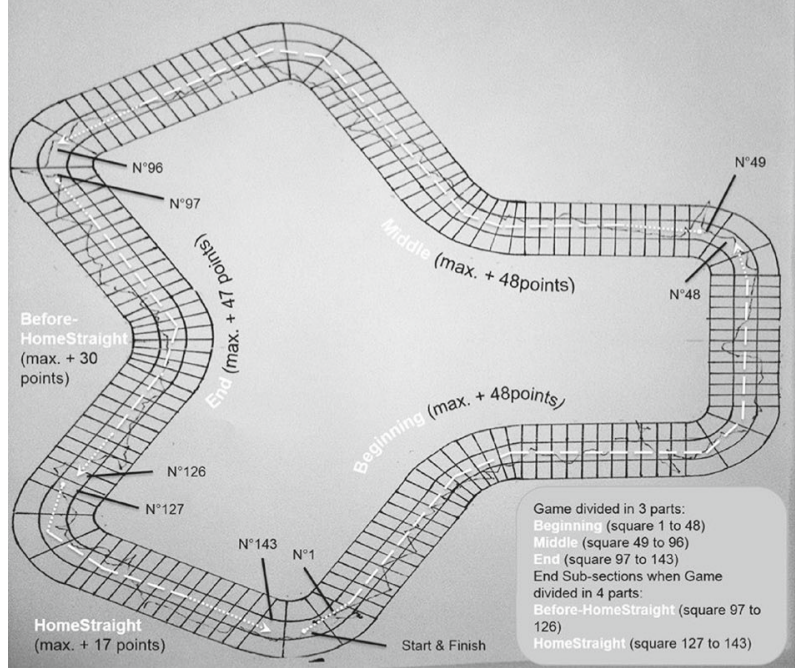

C

\begin{tabular}{|c|c|}
\hline 6 & $\begin{array}{c}\text { Excellent } \\
\text { (Ottimo) }\end{array}$ \\
\hline 5,5 & $\begin{array}{c}\text { Very good } \\
\text { (Molto buono) }\end{array}$ \\
\hline 5 & $\begin{array}{c}\text { Good } \\
\text { (Buono) }\end{array}$ \\
\hline 4,5 & $\begin{array}{c}\text { Average } \\
\text { (Discreto) }\end{array}$ \\
\hline 4 & $\begin{array}{c}\text { Pass } \\
\text { (Sufficiente) }\end{array}$ \\
\hline 3,5 & $\begin{array}{c}\text { Unsatisfactory } \\
\text { (Insufficiente) }\end{array}$ \\
\hline 3 & $\begin{array}{c}\text { Very } \\
\text { Unsatisfactory } \\
\text { (Molto } \\
\text { insufficiente) }\end{array}$ \\
\hline 2,5 & $\begin{array}{c}\text { Bad } \\
\text { (Male) }\end{array}$ \\
\hline 2 & $\begin{array}{c}\text { Very bad } \\
\text { (Molto male) }\end{array}$ \\
\hline
\end{tabular}




\section{References}

Anderman, E. M., \& Midgley, C. (1997). Changes in achievement goal orientations, perceived academic competence, and grades across the transition to middle-level schools. Contemporary Educational Psychology, 22, 269-298.

Anderman, E. M., \& Young, A. J. (1993, April). A multilevel model of adolescents' motivation and strategy use in academic domains. Paper presented at the Annual Meeting of the American Educational Research Association, Atlanta.

Bales, R. F. (1950). A set of categories for the analysis of small group interaction. American Sociological Review, $15,257-263$.

Bandura, A. (1986). Social foundations of thought and action: a social cognitive theory. Englewood Cliffs (NJ): Prentice-Hall.

Bargh, J. A., \& Chartrand, T. L. (2000). The mind in the middle: a practical guide to priming and automaticity research. In H. T. Reis \& C. M. Judd (Eds.), Handbook of research methods in social and personality psychology. New York: Cambridge University Press.

Barron, B. (2000). Coordination in collaborative problem-solving groups. The Journal of the Learning Sciences, 9, 403-436.

Baumeister, R. F. (1984). Choking under pressure: self-consciousness and paradoxical effects of incentives on skilful performance. Journal of Personality and Social Psychology, 46, 610-620.

Blandin, Y. (2002). L'apprentissage par observation d'habiletés motrices: un processus d'apprentissage spécifique? L'Année Psychologique, 102, 523-554.

Brody, C., \& Smith-Lovin, L. (1989). Interruptions in group discussions: the effects of gender and group composition. American Sociological Review, 54, 424-435.

Brookhart, S. M. (2004). Assessment theory for college classrooms. New Directions for Teaching and Learning, $100,5-14$.

Buchs, C., Butera, F., \& Mugny, G. (2004). Resource interdependence, student interactions and performance in cooperative learning. Educational Psychology, 24, 291-314.

Buchs, C., Gilles, I., Dutrévis, M., \& Butera, F. (2011). Pressure to cooperate: is positive reward interdependence really needed in cooperative learning? British Journal of Educational Psychology, 81, 135-146.

Butera, F., Darnon, C., Buchs, C., \& Muller, D. (2006). Les méfaits de la compétition: comparaison sociale et focalisation dans l'apprentissage. In Joule, R.-V., \& Huguet, P. (Eds), Bilan et Perspectives en Psychologie Sociale (pp. 15-44). Grenoble: PUG.

Butler, R. (1987). Task-involving and ego-involving properties of evaluation: effects of different feedbacks conditions on motivational perceptions, interest, and performance. Journal of Educational Psychology, 79, $474-482$.

Crouzevialle, M., \& Butera, F. (2013). Performance-approach goals deplete working memory and impair cognitive performance. Journal of Experimental Psychology: General, 142, 666-678.

Darnon, C., \& Butera, F. (2007). Learning or succeeding? Conflict regulation with mastery or performance goals. Swiss Journal of Psychology, 66, 145-152.

Darnon, C., Muller, D., Schrager, S. H., Pannuzzo, N., \& Butera, F. (2006). Mastery and performance goals predict epistemic and relational conflict regulation. Journal of Educational Psychology, 98, 766-776.

Doise, W., \& Mugny, G. (1981). Le Développement Social de l'intelligence. Paris: InterEditions.

Doise, W., \& Mugny, G. (1984). The social development of the intellect. Oxford: Pergamon Press.

Doise, W., \& Mugny, G. (1997). Le jeu coopératif et la coordination d'actions indépendantes. In Psychologie Sociale \& développement cognitif (pp.47-74). Liège : Armand Colin.

Dunbar, N. E., \& Burgoon, J. K. (2005). Perceptions of power and interactional dominance in interpersonal relationships. Journal of Social and Personal Relationships, 22, 207-233.

Forman, E. A., \& Cazden, C. B. (1985). Exploring Vygotskian perspectives in education: the cognitive value of peer interaction. In J. V. Wertsch (Ed.), Culture, communication, and cognition: Vygotskian perspectives (pp. 323-347). New York: Cambridge University Press.

Harackiewicz, J. M., Barron, K. E., \& Elliot, A. J. (1998). Rethinking achievement goals: when are they adaptive for college students and why? Educational Psychologist, 33, 1-21.

Hawley, P. H. (1999). The ontogenesis of social dominance: a strategy-based evolutionary perspective. Developmental Review, 19, 97-132.

Hawley, P. H. (2002). Social dominance and prosocial and coercive strategies of resource control in preschoolers. International Journal of Behavioral Development, 26, 167-176.

Hayek, A. S., Toma, C., Oberlé, \& Butera, F. (2014). The effect of grades on the preference effect. Basic and Applied Social Psychology, 36, 544-552.

Hayek, A.-S., Toma, C., Oberlé, D., \& Butera, F. (2015). Grading hampers cooperative information sharing in group problem solving. Social Psychology, 46, 121-131.

Hayes, A. F. (2013). Introduction to mediation, moderation, and conditional process analysis. New York: The Guilford Press. 
Johnson, D. W., \& Johnson, R. T. (2009). An educational psychology success story: social interdependence theory and cooperative learning. Educational Researcher, 38, 365-379.

Johnson, D. W., Johnson, R. T., \& Smith, K. (2007). The state of cooperative learning in postsecondary and professional settings. Educational Psychology Review, 19, 15-29.

Kohn, A. (1993). Why incentive plans cannot work. Harvard Business Review, 71, 54-63.

Leffler, A., Gillespie, D. L., \& Conaty, J. C. (1982). The effects of status differentiation on nonverbal behavior. Social Psychology Quarterly, 45, 153-161.

Leman, P. J. (2015). How do groups work? Age differences in performance and the social outcomes of peer collaboration. Cognitive Science, 39, 804-820.

McGrath, J. E., Arrow, H., \& Berdahl, J. L. (1999). Cooperation and conflict as manifestations of coordination in small groups. Polish Psychological Bulletin, 30, 1-14.

Midgley, C., Anderman, E., \& Hicks, L. (1995). Differences between elementary and middle school teachers and students: a goal theory approach. Journal of Early Adolescence, 15, 90-113.

Mugny, G., \& Doise, W. (1978). Socio-cognitive conflict and structure of individual and collective performances. European Journal of Social Psychology, 8, 181-92.

Mugny, G., Butera, F., Quiamzade, A., Dragulescu, A., \& Tomei, A. (2003). Comparaisons sociales des compétences et dynamiques d'influence sociale dans les tâches d'aptitude. L'Année Psychologique, 104, 469-496.

Muller, D., \& Butera, F. (2007). The focusing effect of self-evaluation threat in coaction and social comparison. Journal of Personality and Social Psychology, 93, 194-211.

Nicholls, J. G. (1979). Quality and equality in intellectual development: the role of motivation in education. American Psychologist, 34, 1071-1084.

Nicholls, J. G. (1983). Conceptions of ability and achievement motivation: a theory and its implications for education. In S. G. Paris, G. M. Olson, \& H. W. Stevenson (Eds.), Learning and motivation in the classroom (pp. 211-237). Hillsdale, NJ: Erlbaum.

Pintrich, P. R. (2000). An achievement goal theory perspective on issues in motivation terminology, theory, and research. Contemporary Educational Psychology, 25, 92-104.

Pollock, B. J., \& Lee, T. D. (1992). Effects of the model's skill level on observational learning. Research Quarterly for Exercise and Sport, 63, 25-29.

Psaltis, C., \& Zapiti, A. (2014). Interaction, communication and development: psychological development as a social process. London: Routledge.

Pulfrey, C., Buchs, C., \& Butera, F. (2011). Why grades engender performance-avoidance goals: the mediating role of autonomous motivation. Journal of Educational Psychology, 103, 683-700.

Pulfrey, C., Darnon, C., \& Butera, F. (2013). Autonomy and task performance: explaining the impact of grades on intrinsic motivation. Journal of Educational Psychology, Published Online.

Roseth, C. J., Johnson, D. W., \& Johnson, R. T. (2008). Promoting early adolescents' achievement and peer relationships: the effects of cooperative, competitive, and individualistic goal structures. Psychological Bulletin, 134, 223-246.

Rubin, K. H., \& Rose-Krasnor, L. (1992). Interpersonal problem solving. In V.B.V. Hassett \& M. Hersen (Eds.), Handbook of social development (pp. 283-323). New York: Plenum.

Rucker, D. D., Preacher, K. J., Tormala, Z. L., \& Petty, R. E. (2011). Mediation analysis in social psychology: current practices and new recommendations. Social and Personality Psychology Compass, 5(6), 359-371.

Schmid Mast, M. (2002). Dominance as expressed and inferred through speaking time. Human Communication Research, 28, 420-450.

Tusing, K. J., \& Dillard, J. P. (2000). The sounds of dominance: vocal precursors of perceived dominance during interpersonal influence. Human Communication Research, 26, 148-171.

Walton, G. M., \& Cohen, G. L. (2003). Stereotype lift. Journal of Experimental Social Psychology, 39, 456-467.

Zapiti, A., \& Psaltis, C. (2012). Asymmetries in peer interaction: the effect of social representations of gender and knowledge asymmetry on children's cognitive development. European Journal of Social Psychology, 42, 578-588.

Dr. Anne-Sophie Hayek. Institut des Sciences Sociales, Université de Lausanne, Lausanne, Switzerland.

Current themes of research:

Cooperation and competition. Group processes. Grading.

Most relevant publications: 
Hayek, A. S., Toma, C., Oberlé, D., \& Butera, F. (2014). The effect of grades on the preference effect: grading reduces consideration of disconfirming evidence. Basic and Applied Social Psychology, 36, 544-552.

Hayek, A. S., Toma, C., Oberlé, D., \& Butera, F. (2015). Grading hampers cooperative information sharing in group problem solving. Social Psychology, 46, 121-131.

Dr. Claudia Toma. Université Libre de Bruxelles, Brussel, Belgium.

Current themes of research:

Cooperation and competition. Group processes. Judgement and decision making.

Most relevant publications:

Toma, C., \& Butera, F. (2009). Hidden profiles and concealed information: strategic information sharing and use in group decision making. Personality and Social Psychology Bulletin, 35, 793-806.

Toma, C., \& Butera, F. (2015). Cooperation versus competition effects on information sharing and use in group decision making. Social and Personality Psychology Compass, 9, 455-467.

Ms. Sofia Guidotti. Institut des Sciences Sociales, Université de Lausanne, Lausanne, Switzerland.

Current themes of research:

Cooperation. Grading.

Most relevant publications:

Dr. Dominique Oberlé. Université de Paris Ouest Nanterre La Défense, Nanterre, France.

Current themes of research:

Group processes and group dynamics.

Most relevant publications:

Aebischer, V., \& Oberlé, D. (2012). Le groupe en psychologie sociale (4th edition). Paris: Dunod. Augustinova, M., \& Oberlé, D. (2013). Psychologoe sociale du groupe au travail. Bruxelles: De Boeck.

Dr. Fabrizio Butera. Institut des Sciences Sociales, Université de Lausanne, Lausanne, Switzerland. Email:Fabrizio.Butera@unil.ch

Current themes of research:

Learning. Motivation. Conflict. Social influence.

Most relevant publications:

Pulfrey, C., Buchs, C., \& Butera, F. (2011). Why grades engender performance avoidance goals: the mediating role of autonomous motivation. Journal of Educational Psychology, 103, 683-700.

Pulfrey, C., Darnon, C., \& Butera, F. (2013). Autonomy and task performance: explaining the impact of grades on intrinsic motivation. Journal of Educational Psychology, 105, 39-57. 